\title{
PODER DE MERCADO NO SEGMENTO DE AUTOMÓVEIS ATÉ 1000 \\ CILINDRADAS: UMA ANÁLISE A PARTIR DA NOVA ORGANIZAÇÃO INDUSTRIAL EMPÍRICA
}

\section{MARKET POWER IN THE AUTOMOBILE SEGMENT UP TO 1000 CC: AN ANALYSIS FROM THE NEW EMPIRICAL INDUSTRIAL ORGANIZATION}

\author{
Kamila Gabriela Jacob ${ }^{1}$ \\ Jader Fernandes Cirino ${ }^{2}$ \\ Rosangela Aparecida Soares Fernandes ${ }^{3}$ \\ Marcelo José Braga ${ }^{4}$
}

\begin{abstract}
Resumo
Nesse estudo buscou-se verificar a existência e caracterizar o tipo de poder de mercado no setor automobilístico brasileiro, especificamente no segmento de carros populares (1000 cc). Para tal, foi utilizado o modelo Cotterill, Franklin e Ma (1996), o qual considera esse segmento um mercado oligopolizado com produtos diferenciados, respaldado pela Nova Organização Industrial Empírica (New Empirical Industrial Organization - NEIO). Os resultados obtidos mostram que, quando analisadas as elasticidades cruzadas, o segmento pode ser separado em dois mercados, no qual Gol e o Pálio competem entre si, assim como o Celta e o Uno, caracterizando-se como bens substitutos um do outro. Com relação ao poder de mercado, dividido entre unilateral e cooperativo, conclui-se que o Gol possui maior poder de mercado unilateral, apresentando também o maior poder de mercado total. A partir do coeficiente de Chamberlin para conluio, verificou-se a concorrência entre Gol e Palio e a cooperação entre Uno e Celta.
\end{abstract}

Palavras-chave: Poder de Mercado; Carros Populares; Produtos Diferenciados;

\begin{abstract}
This study aims to verify the existence and to characterize the type of market power in the Brazilian automotive industry, specifically in the popular car segment $(1000 \mathrm{cc})$. For that, it was used the model Cotterill, Franklin and Ma (1996) which considers an oligopoly market with differentiated products, supported by the New Industrial Organization Empirical (NEIO). The results show that when the cross-elasticities are analyzed, the segment can be separated into two markets where in which the Gol and the Palio compete, as well as the Celta and the Uno, characterized as substitute goods from each other. In relation to the market power, divided in unilateral and cooperative, the Gol had greater power of unilateral market, and it also had the greatest power of the total market. Based on the Chamberlin coefficient for collusion, it was observed competition between the Gol and the Palio, and cooperation between Uno and Celta.
\end{abstract}

Key words: Market Power; Popular Car; Differentiated Products.

Área 1: Competição, preços e estruturas de mercado.

Classificação JEL: D4; D43; L10; L11

\footnotetext{
${ }^{1}$ Professora Substituta do Departamento de Ciências Econômicas e Gerenciais da Universidade Federal de Ouro Preto.

${ }^{2}$ Professor Adjunto do Departamento de Economia da Universidade Federal de Viçosa.

${ }^{3}$ Professora Adjunta III do Departamento de Ciências Econômicas e Gerenciais da Universidade Federal de Ouro Preto.

${ }^{4}$ Professor Associado II do Departamento de Economia Rural da Universidade Federal de Viçosa.
} 


\section{Introdução}

Com base nos dados da Associação Nacional dos Fabricantes de Veículos ANFAVEA (2014), a indústria automobilística brasileira teve um faturamento acima de US\$ 100 bilhões de dólares, representando aproximadamente 25\% do PIB industrial e 5\% do PIB total, o que resulta em uma contribuição expressiva para a economia do país.

A indústria de automóveis é dividida em duas grandes categorias, os autoveículos e as máquinas agrícolas e rodoviárias (ANFAVEA, 2014). Na categoria dos autoveículos, destacam-se os carros com motorização até 1.000 cilindradas (1000cc), surgidos no Brasil na década de noventa, também conhecidos como "carros populares". Segundo os dados da ANFAVEA (2014), entre 1990 e 2013, ocorreu um aumento de aproximadamente $440 \%$ em automóveis 1000 cc, ou 1.0, licenciados.

A expressiva quantidade de licenciamento dos carros populares no Brasil ocorreu, principalmente, devido às medidas governamentais de redução do Imposto sobre Produtos Industrializados (IPI) para veículos com motor até 1.000 cilindradas $^{5}$ e ao incentivo do governo ao processo do aumento do poder aquisitivo para a população de baixa renda e às facilidades dos créditos (CERQUEIRA, SILVA, FARIAS, 2013).

Com base nas estatísticas da ANFAVEA (2005-2010), é possível observar que quatro modelos de automóveis dominavam o mercado de carros populares naquele período: o Celta da General Motors Do Brasil Ltda, o Gol, da Volkswagen Do Brasil Ltda, o Pálio e o Uno, da montadora italiana Fiat Automóveis S.A. (Cf. Anexo 1). Ao analisar a concentração de mercado (CRk) nos anos de recorte da análise (2005-2010), observa-se uma queda significativa no índice de concentração para os quatro modelos de carros populares (CR4 de 77,54\% em 2005 para 56,73\% em 2010). Entretanto, mesmo apresentando uma queda, na média, o CR4 dos quatro modelos de carros mais vendidos nesses seis anos foi de $66,81 \%$ o que, segundo Martin (2010), poderia ser considerado como um mercado oligopolizado (CR4 acima de $40 \%)$.

Além dos índices de concentração elevados, que caracteriza-se como uma das primeiras aproximações para avaliar a existência de poder de mercado ${ }^{6}$, o mercado automobilístico possui características microeconômicas que propiciam o comportamento anticoncorrencial por parte dos seus agentes: presença de barreiras à entrada, baixa possibilidade de substituição do produto e demanda inelástica com relação aos preços ${ }^{7}$. Nesse contexto, torna-se relevante verificar as possíveis evidências de poder de mercado entre as montadoras na indústria automobilística brasileira.

No Brasil, há vários trabalhos na literatura que buscaram investigar o poder de mercado na indústria automobilística utilizando diferentes metodologias (SILVA et al., 2008; COSTA \& ROSA, 2007; FARIAS, 2008. Entretanto, esse artigo, diferencia-se dos demais por verificar a existência do poder de mercado considerando produtos heterogêneos e, por caracterizar o tipo de poder de mercado, permitindo avaliar estratégias como: esforços para diferenciação de produto (verificada por meio do poder de mercado unilateral) e exposição da reação das outras empresas diante das variações no preço (por meio do poder de mercado cooperativo e ou de conluio).

\footnotetext{
${ }^{5}$ Cf. Alves e Wilbert (2014) para maiores informações sobre as alterações das alíquotas do IPI vigentes para os carros populares de 2008 a 2014.

${ }^{6}$ De acordo com o modelo Estrutura-Conduta-Desempenho (ECD), quanto maior a concentração da oferta, (estrutura) maior a probabilidade de colusão (conduta) e, dessa forma, preços e lucros mais elevados.

${ }^{7}$ Quanto mais inelástica for a demanda, isto é, menos sensível for o consumidor a alterações no preço do produto, maior a capacidade da empresa de elevar esse último sem que isso acarrete reduções significativas na quantidade vendida.
} 
A análise realizada compreende o período entre 2005 e 2010, pois como mostrado por Gabriel et al (2011), o período entre 2004 e meados de 2008 é o mais recente dentre os períodos que destacam-se quanto ao aumento da produção de veículos ${ }^{8}$. Mais especificamente, com relação ao mercado de carros populares, o período analisado marca o surgimento e a consolidação dos carros populares flex fuel, e a primeira redução do IPI (ocorrida entre dezembro de 2008 e dezembro de 2010) como medidas de estímulo a demanda desses veículos para aquecimento da economia. Quanto ao Mercado relevante ${ }^{9}$, a delimitação utilizada está em conformidade com o Conselho Administrativo de Defesa EconômicaCADE $(2001)^{10}$ que define o mercado relevante geográfico de automóveis e suas peças envolvidas como de domínio nacional. Para a delimitação na dimensão produto, ao se considerar produtos diferenciados, como na indústria automobilística, cada produto deve ser tratado como um mercado (VIDEIRA, 2005).

Com base nas peculiaridades para a indústria automobilística supracitadas, e para o segmento de carros populares, esse estudo visou analisar a existência e o tipo de poder de mercado no segmento de veículos flex fuel até 1.000 cilindradas (carros populares), no período compreendido entre janeiro de 2005 e dezembro de 2010.

\section{Referencial teórico}

\subsection{Poder de Mercado por marca Unilateral e Coordenado - O modelo CFM}

O modelo de Cotterill, Franklin e Ma - CFM (1996) foi elaborado para a análise da demanda em mercado oligopolizado com produtos diferenciados (heterogêneos) e possui vantagens sobre os modelos de sistema de demandas residuais ${ }^{11}$ e sistemas de demanda unilateral $^{12}$. Com relação ao primeiro, a sua vantagem é a flexibilidade, pois pode ser utilizado para quaisquer conjeturas de reação das demais marcas. O sistema de demanda residual sobressai-se por possibilitar a separação dos poderes unilateral e cooperativo. Ademais, o modelo CFM comprova que tanto o sistema de demanda unilateral quanto o residual eram casos específicos do modelo mais geral desenvolvido por eles (AGUIAR, 2000).

O modelo CFM assume parte do pressuposto de que há uma indústria com produtos diferenciados e atuando em competição de Bertrand. Para isso, assumiram o preço como variável estratégica, de modo que a demanda para a marca 1 em uma indústria com n marcas é apresentada por:

$$
q_{1}=q_{1}\left(p_{i}, \ldots, p_{n}, D\right)
$$

em que, $q_{1}$ é a quantidade da marca $1, p_{i}$ é o preço da marca $i(\mathrm{i}=1, \ldots, \mathrm{n})$ e $D$ é um vetor de variáveis adicionais que causam o deslocamento da demanda.

Encontra-se a expressão em função das elasticidades após derivar a equação (1) em relação à $\mathrm{p}_{1}$ (regra da cadeia) e realizar algumas manipulações algébricas:

\footnotetext{
${ }^{8}$ Gabriel et al. (2011) mostram que o período compreendo entre 2004 e meados de 2008 é destaque para a produção automobilística por apresentar um aquecimento do mercado externo e doméstico desse produto.

${ }^{9}$ De acordo com o Guia para Análise Econômica de Atos de Concentração Horizontal (Portaria Conjunta SEAE/SDE $n^{\circ} 50$, de $1^{\circ}$ de agosto de 2001), o Mercado relevante é “o menor grupo de produtos e a menor área geográfica necessários para que um suposto monopolista esteja em condições de impor um 'pequeno, porém, significativo e não transitório’ aumento de preços”.

${ }^{10}$ Parecer ao processo Administrativo protocolado pelo CADE (fls.03-89) no ano de 2001.

${ }^{11}$ Segundo Baker e Bresnahan (1985), entende-se a função de demanda residual como a relação entre o preço e a quantidade de uma empresa, tendo em conta a resposta da oferta de todas as outras empresas.

${ }^{12}$ O sistema teve origem no trabalho de Cotterrill e Haller (1997) e resulta do poder de mercado unilateral, no qual o produto usufrui de poder de mercado por não existir bens substitutos para esse ou pelo fato dos consumidores julgarem que os produtos similares não são bons o suficiente.
} 


$$
\eta_{1}^{o}=\eta_{11}+\eta_{12} \cdot \varepsilon_{21}+\cdots+\eta_{1 n} \cdot \varepsilon_{n 1}
$$

em que $\eta_{1}^{o}$ é a elasticidade do preço observável pela marca 1 ; $\eta_{11}$ refere-se à elasticidadepreço parcial da demanda da marca 1 ; $\eta_{1 i}$ corresponde a elasticidade-preço cruzada da demanda da marca 1 , em relação aos preços das outras marcas $\left(p_{i}\right)$; $\varepsilon_{i 1}$ é a elasticidade de reação de preços das marcas rivais de 1 , isto é, porcentagem de variação em $p_{i}$, quando $p_{1}$ é alterado em $1 \%$.

Nota-se que a elasticidade do preço observável das marcas possui dois componentes gerais: a elasticidade de preço parcial $\left(\eta_{11}\right)$ e a elasticidade de reação de preço das marcas rivais $\left(\sum_{i=2}^{N} \eta_{1 i} \varepsilon_{i 1}\right)$. A elasticidade de preço parcial mede o quanto a firma analisada (marca 1 ) possui de poder unilateral de mercado, pois as mudanças são geradas apenas por variações no próprio preço, $\mathrm{p}_{1}$.

O componente do lado direito da equação (2), mede o poder de mercado coordenado das elasticidades observáveis das marcas, na qual $\eta_{1 i}$ mostra quanto o preço da firma "i" (com $\mathrm{i}=1$ ) variará de acordo com a alteração de $1 \%$ no preço da marca $\mathrm{j}(\mathrm{j} \neq 1)$. Quando avalia-se apenas $0 \varepsilon_{i 1}$, reação de preços das marcas rivais à marca 1, três casos especiais podem ocorrer. O primeiro, conhecido como Nash-Bertrand, ocorre quando as firmas não reagem à mudança no preço da marca 1 , fazendo com que os valores de $\varepsilon_{i 1}$ sejam iguais a zero. $O$ segundo decorre da cooperação entre as marcas, onde $\varepsilon_{i 1}$ assume valores positivos fazendo com que a elasticidade observável da demanda no mercado torne-se mais inelástica em comparação à unilateral. O terceiro caso ocorre quando há rivalidade, isto é, a elasticidade de reação de preços é negativa e a demanda observável é mais elástica do que a unilateral, o que resulta na redução do poder de mercado da firma analisada.

Para possibilitar melhor compreensão dos diferentes tipos de poder de mercado, Cotterill, Franklin e Ma (1996) ilustram três curvas de demanda relacionadas às elasticidades (observada, a unilateral e o conluio completo) apresentadas na equação (2), para uma marca individual, tendo como referências as situações extremas de competição perfeita e monopólio (Figura 1).

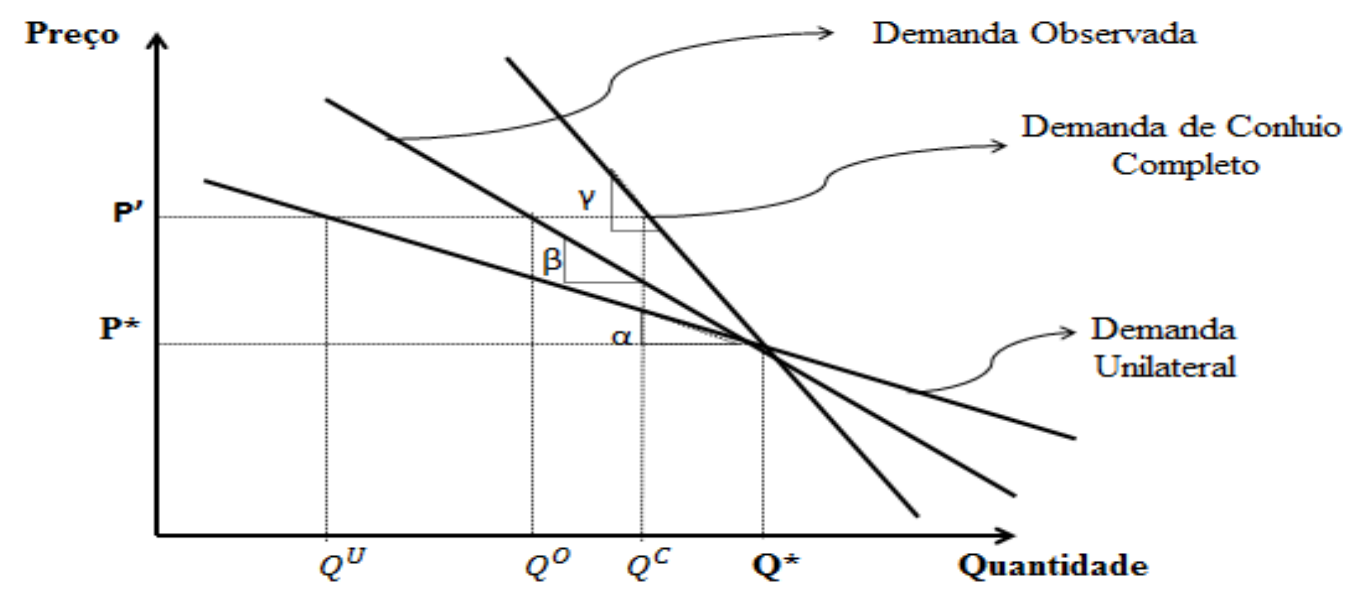

Figura 1: Relação Teórica da Demanda para uma marca em um oligopólio com produtos diferenciados.

Fonte: Cotterill, Franklin e Ma (1996).

Considera-se que as curvas de demanda lineares são boas aproximações das curvas de demanda de mercado e que o ponto de equilíbrio é dado por ( $\left.\mathrm{P}^{*}, \mathrm{Q}^{*}\right)$. Adicionalmente, supõese que o preço da marca aumente de $\mathrm{P}^{*}$ para P'. As três curvas representam, respectivamente, 
a demanda de conluio completo das firmas; a demanda observada, situação onde há algum nível de cooperação, e; a demanda unilateral, quando não há cooperação. Dado o aumento nos preços, a quantidade demandada diminuiria para $\mathrm{Q}^{\mathrm{O}}$ com a elasticidade-preço da demanda observável. Se existisse um perfeito conluio tácito, a quantidade seria reduzida apenas a $\mathrm{Q}^{\mathrm{C}}$, enquanto, na ausência de cooperação, a redução seria em direção a $\mathrm{Q}^{\mathrm{U}}$ (COTTERILL, FRANKLIN e MA, 1996).

No intuito de mensurar o grau de poder de mercado unilateral, sendo esse o poder de mercado da firma que não considera a ação e a reação das firmas concorrentes, Bolter, McConnaughey e Kelsey (1990) desenvolvem o índice de Rothschild (R). O índice R consiste em dividir a inclinação da curva de demanda unilateral (tangente de $\alpha$ ) pela inclinação da curva de demanda com as marcas em conluio (tangente de $\gamma)^{13}$. Dessa forma, considerando variações marginais próximas à variável $P_{1}$, o índice R pode ser calculado pela divisão da elasticidade-preço de plena cooperação pela elasticidade-preço unilateral, como demonstrado na equação (3).

Índice de Rothschild $(\mathrm{R})=\frac{T g \alpha}{T_{g Y}}=\frac{\left(\frac{\Delta P}{\Delta Q}\right)^{U}}{\left(\frac{\Delta \mathrm{P}}{\Delta Q}\right)^{C}}=\frac{\left(\frac{\Delta P}{\Delta Q} \frac{Q}{P}\right)^{U}}{\left(\frac{\Delta P}{\Delta Q} \frac{Q}{P}\right)^{C}}=\frac{\left(\frac{\Delta Q}{\Delta P} \frac{P}{Q}\right)^{C}}{\left(\frac{\Delta \mathrm{Q}}{\Delta \mathrm{P}}\right)^{U}}=\frac{\eta_{1}^{C}}{\eta_{11}}$

em que, $0 \leq R \leq 1$. Sendo $\mathrm{R}$ igual a zero para competição perfeita, a demanda unilateral horizontal, e igual a 1 para colusão total, demanda unilateral com a mesma inclinação da totalmente em conluio (AGUIAR, 2000).

O grau de poder de mercado observável, ou grau de poder de mercado total (que combina o poder de mercado unilateral com o de conluio), é mensurado pelo índice de Cotterill (C), elaborado por Cotterril, Franklin e Ma (1996). O índice C pode ser obtido por meio da divisão da elasticidade de plena cooperação $\left(\eta_{1}^{c}\right)$ pela elasticidade da demanda observável $\left(\eta_{1}^{\circ}\right)$.

$$
\text { Índice de Cotterill (C) }=\frac{T g \beta}{T_{g Y}}=\quad \frac{\left(\frac{\Delta P}{\Delta Q}\right)^{o}}{\left(\frac{\Delta \mathrm{P}}{\Delta Q}\right)^{C}}=\frac{\left(\frac{\Delta P}{\Delta Q} \frac{Q}{P}\right)^{o}}{\left(\frac{\Delta P}{\Delta Q} \frac{Q}{P}\right)^{C}}=\frac{\left(\frac{\Delta Q}{\Delta P} \frac{P}{Q}\right)^{C}}{\left(\frac{\Delta Q}{\Delta \mathrm{P}} \frac{P}{Q}\right)^{o}}=\frac{\eta_{1}^{c}}{\eta_{1}^{O}}
$$

em que, $0 \leq C \leq 1$. Para $C$ igual a 1 , diz-se que o mercado comporta-se como monopólio e, quando $\mathrm{C}$ é igual a 0 , pode-se identificar duas possibilidades. A primeira, que não existe poder de mercado. A segunda, o poder de mercado unilateral está sendo plenamente compensado pela concorrência entre as marcas (AGUIAR, 2000).

Cotterril, Franklin e Ma (1996) decompõem, ainda, o poder de mercado observável em proporção do poder de mercado de conluio (ou cooperação), por meio da redução da produção ou por aumento no preço do produto (AGUIAR, 2000). Isto é, denominado como quociente de Chamberlin $(\mathrm{CH})$, o poder de mercado corporativo corresponde à parcela do poder de mercado observável que não provém do poder unilateral:

$$
\text { Chamberlin }(\mathrm{CH})=\frac{c-R}{c}=1-\frac{\eta_{1}^{0}}{\eta_{11}}
$$

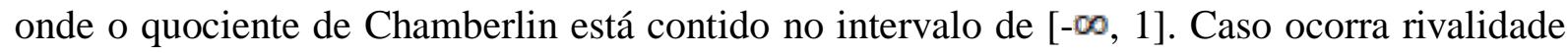
entre as marcas, a elasticidade-preço da demanda observável ( $\eta_{1}^{o}$ ) será maior em módulo comparado à elasticidade unilateral $\left(\eta_{11}\right)$ e o quociente $\mathrm{CH}$ será negativo. Todavia, se não

\footnotetext{
${ }^{13}$ Para melhor compreensão do índice de Rothscild (R), ver Bolter, McConnaughey e Kelsey (1990) e Greer (1984, pág. 94).
} 
existir conluio entre as marcas que atuam no mercado, $\eta_{1}^{o}$ será igual a $\eta_{11}$ e o $\mathrm{CH}$ será zero. Por fim, se houver algum tipo de poder de conluio, o $\mathrm{CH}$ variará entre zero e 1 , e o valor dependerá da proporção do poder observável de mercado que estará atrelado à colusão, isto é, o CH assumirá valor igual a 1 no caso de conluio completo entre as marcas.

\section{Metodologia}

\subsection{Modelo analítico}

Os valores das elasticidades do modelo CFM são obtidos por meio da estimação de dois tipos de equações: demandas e de reações de preços dos modelos de carros. Por meio da equação de demanda, obtém-se os parâmetros das elasticidades $\eta_{i i}$ e $\eta_{i j}$. Os parâmetros $\varepsilon_{j i}$ são obtidos pela estimação das equações de reações de preço.

Para estimar a equação de demanda dos carros populares, foi utilizado o Quadratic Almost Ideal Demand System (QUAIDS), Sistema de demanda quase linear quadrático desenvolvido por Blundell, Pachardes e Weber (1993) e Banks, Blundell e Lewbel (1997). O modelo QUAIDS utiliza a generalização da demanda que possui parcelas do dispêndio, lineares no logaritmo total do dispêndio (ln X), chamadas por Muellbauer (1976) de PriceIndependent Generalized Logarithmic (PIGLOG) (BANKS, BLUNDELL E LEWBEL, 1997).

Desse modo, a forma geral da demanda obtida, por meio do modelo QUAIDS, consistente com a evidência empírica sobre curvas de Engel é dada por Banks, Blundell e Lewbel (1997) como:

$$
w_{i}(p, x)=\alpha_{0}+\sum_{j} \gamma_{i j} \ln p_{j}+\beta_{i} \ln (X / P)+\frac{\lambda_{i}}{b(p)}\left\{\ln \left[\frac{X}{P}\right]\right\}^{2}
$$

para bens $i=1, \ldots, N$, em que, $w_{i}$ fornece a parcela de dispêndio da marca $i$ na despesa total, isto é, a razão entre a receita da marca i e receita da indústria $(\mathrm{X}) ; p_{j}$ é o preço da marca $j$; X é o dispêndio (receita) total com o grupo de produtos analisados; $P$ é o índice de preços determinado na forma de uma função translog $\alpha_{0}$, no princípio, era para ser calculado junto aos demais parâmetros, porém, na prática, essa tarefa é muito difícil, sendo utilizada, assim, como em Deanton e Muellbauer (1980) e Banks, Blundell e Lewbel (1997) o valor de "alfa" como o menor valor do logaritmo do dispêndio e $\gamma_{i j}$ e $\beta_{i}$ como parâmetros a serem estimados.

As elasticidades no modelo QUAIDS, elasticidade dispêndio e preço da demanda, são determinadas a partir da derivação da equação (6) quanto a $\ln X$ e $\ln \mathrm{P}_{\mathrm{j}}$, tal que (Banks, Blundell e Lewbel (1997):

$$
\begin{gathered}
\eta_{i i}=\frac{\partial w_{i}}{\partial \ln X}=\beta_{i}+\frac{2 \lambda_{i}}{b(p)}\left\{\ln \left[\frac{X}{P}\right]\right\} \\
\eta_{i j}=\frac{\partial w_{i}}{\partial \ln p_{j}}=\gamma_{i j}-\mu_{i}\left(\alpha_{j}+\sum_{k} \gamma_{j k} \ln p_{k}\right)-\frac{\lambda_{i} \beta_{j}}{b(p)}\left\{\ln \left[\frac{X}{P}\right]^{2}\right\}
\end{gathered}
$$

com definições previamente apresentadas. No que se refere à elasticidade-renda ou, mais especificamente, elasticidade dispêndio, tem-se:

$$
e_{i}=\left(\frac{\eta_{i i}}{w_{i}}\right)+1
$$

Dado que as elasticidades-preço utilizadas no modelo CFM mantêm a renda constante, estima-se apenas as elasticidades-preço não compensadas, dadas por: 


$$
e_{i j}=\left(\frac{\eta_{i j}}{w_{i}}\right)-\delta_{i j}
$$

onde o parâmetro $\delta_{i j}=0$ para todo $\mathrm{i} \neq \mathrm{j}$; e $\delta_{i j}=1$ para todo $\mathrm{i}=\mathrm{j}$.

De acordo com Aguiar (2000), pode-se estimar as equações de reação de preço tendo em cada equação um preço como variável explicada e os demais preços como variáveis explicativas. Assim, as equações de preços em função das elasticidades de reação de preços $\left(\varepsilon_{i j}\right)$ ficam da seguinte forma:

$$
\begin{gathered}
\ln p_{1}=\theta_{1}+\varepsilon_{12} \ln p_{2}+\varepsilon_{13} \ln p_{3}+\cdots+\varepsilon_{1 n} \ln p_{n} \\
\ln p_{2}=\theta_{2}+\varepsilon_{21} \ln p_{1}+\varepsilon_{23} \ln p_{3}+\cdots+\varepsilon_{2 n} \ln p_{n} \\
\vdots \\
\ln p_{n}=\theta_{n}+\varepsilon_{n 1} \ln p_{1}+\varepsilon_{n 2} \ln p_{2}+\cdots+\varepsilon_{n(n-1)} \ln p_{n-1}
\end{gathered}
$$

Não obstante, o modelo CFM obtém as elasticidades de plena cooperação assumindo que as marcas (1, 2 e 3, por exemplo) são dirigidas pela mesma firma, as quais decidem os preços $\left(p_{1}, p_{2}, p_{3}\right)$ de modo a maximizar o lucro conjunto. Dessa forma, a função de lucro para firma é dada por:

$$
\pi=p_{1} q_{1}+p_{2} q_{2}+p_{3} q_{3}-c\left(q_{1}, q_{2}, q_{3}\right)
$$

em que $c\left(q_{1}, q_{2}, q_{3}\right)$ corresponde à função de custos das marcas 1 , 2 e 3 .

Respeitando a condição de primeira ordem para a maximização de lucro da firma, temse:

$$
\begin{aligned}
& \frac{\partial \pi}{\partial p_{1}}=q_{1}+p_{1} \frac{\partial q_{1}}{\partial p_{1}}+p_{2} \frac{\partial q_{2}}{\partial p_{1}}+p_{3} \frac{\partial q_{3}}{\partial p_{1}}-\frac{\partial c}{\partial q_{1}} \frac{\partial q_{1}}{\partial p_{1}}-\frac{\partial c}{\partial q_{2}} \frac{\partial q_{2}}{\partial p_{1}}-\frac{\partial c}{\partial q_{3}} \frac{\partial q_{3}}{\partial p_{1}} \\
& \frac{\partial \pi}{\partial p_{1}}=q_{2}+p_{1} \frac{\partial q_{1}}{\partial p_{2}}+p_{2} \frac{\partial q_{2}}{\partial p_{2}}+p_{3} \frac{\partial q_{3}}{\partial p_{2}}-\frac{\partial c}{\partial q_{1}} \frac{\partial q_{1}}{\partial p_{2}}-\frac{\partial c}{\partial q_{2}} \frac{\partial q_{2}}{\partial p_{2}}-\frac{\partial c}{\partial q_{3}} \frac{\partial q_{3}}{\partial p_{2}} \\
& \frac{\partial \pi}{\partial p_{1}}=q_{3}+p_{1} \frac{\partial q_{1}}{\partial p_{3}}+p_{2} \frac{\partial q_{2}}{\partial p_{3}}+p_{3} \frac{\partial q_{3}}{\partial p_{3}}-\frac{\partial c}{\partial q_{1}} \frac{\partial q_{1}}{\partial p_{3}}-\frac{\partial c}{\partial q_{2}} \frac{\partial q_{2}}{\partial p_{3}}-\frac{\partial c}{\partial q_{3}} \frac{\partial q_{3}}{\partial p_{3}}
\end{aligned}
$$

Denominando $w_{i}=\frac{p_{i} q_{i}}{\sum p_{i} q_{i}}, c m g_{i}=\frac{\partial c}{\partial q_{i}}, p c m_{i}=\frac{p_{i}-c m g_{i}}{p_{i}}$ (poder der mercado), com $i=$ 1,2,3 e realizando algumas manipulações algébricas, obtém-se o seguinte sistema:

$$
\begin{aligned}
& w_{1}+w_{1} \eta_{11} p c m_{1}+w_{2} \eta_{21} p c m_{2}+w_{3} \eta_{31} p c m_{3}=0 \\
& w_{2}+w_{1} \eta_{12} p c m_{1}+w_{2} \eta_{22} p c m_{2}+w_{3} \eta_{32} p c m_{3}=0 \\
& w_{3}+w_{1} \eta_{13} p c m_{1}+w_{2} \eta_{23} p c m_{2}+w_{3} \eta_{33} p c m_{3}=0
\end{aligned}
$$

Nesse caso, tendo obtido as concentrações de mercado de cada marca, por meio do cálculo CR4 e as elasticidades-preço da demanda unilateral, por meio da estimação da demanda no modelo QUAIDS citada, o sistema torna-se possível de solução para os três pcm's. Para obter a elasticidade de plena cooperação, deve-se considerar que, se as três marcas estão em equilíbrio, os pmc's serão o negativo do inverso da elasticidade de plena cooperação, sendo resolvidos por meio cálculos triviais (FARIAS, 2008). Como exposto, a elasticidade de cooperação é dada por:

$$
-\frac{1}{\eta_{1}^{C}}=\frac{p_{i}-c m g_{i}}{p_{i}}
$$


Estima-se conjuntamente as equações de demanda (numeradas de (16) até (19)) para a estimação da elasticidade-preço direta e cruzada:

$$
\begin{aligned}
& W_{\text {pat }}=\alpha_{1}+\gamma_{11} \ln \left(P_{\text {pat }}\right)+\gamma_{12} \ln \left(P_{\text {golt }}\right)+\gamma_{13} \ln \left(P_{\text {unot }}\right)+\gamma_{14} \ln \left(P_{\text {cet }}\right)+\beta_{1} \ln (X / P L) \\
& +\frac{\lambda_{1}}{b(p)}\left\{\ln \left[\frac{X}{P}\right]\right\}^{2}+\phi_{11} V_{\text {pat }}+\phi_{12} V_{\text {golt }}+\phi_{13} V_{\text {unot }}+\phi_{14} V_{\text {cat }}+\phi_{15} \text { CO }_{\text {fiatt }} \\
& +\phi_{16} \mathrm{CO}_{g m t}+\phi_{17} \mathrm{CO}_{v w t}+\psi_{p a} \\
& W_{\text {golt }}=\alpha_{2}+\gamma_{21} \ln \left(P_{\text {pat }}\right)+\gamma_{22} \ln \left(P_{\text {golt }}\right)+\gamma_{23} \ln \left(P_{\text {unot }}\right)+\gamma_{24} \ln \left(P_{\text {cot }}\right)+\beta_{2} \ln (X / P L) \\
& +\frac{\lambda_{2}}{b(p)}\left\{\ln \left[\frac{X}{P}\right]\right\}^{2}+\phi_{21} V_{\text {pat }}+\phi_{22} V_{\text {golt }}+\phi_{23} V_{\text {unot }}+\phi_{24} V_{\text {cet }}+\phi_{25} \operatorname{CO}_{\text {fiatt }} \\
& +\phi_{26} \mathrm{CO}_{g m t}+\phi_{27} \mathrm{CO}_{v w t}+\psi_{g o l} \\
& W_{\text {unot }}=\alpha_{3}+\gamma_{31} \ln \left(P_{\text {pat }}\right)+\gamma_{32} \ln \left(P_{\text {golt }}\right)+\gamma_{33} \ln \left(P_{\text {unot }}\right)+\gamma_{34} \ln \left(P_{\text {cot }}\right)+\beta_{3} \ln (X / P L) \\
& +\frac{\lambda_{3}}{b(p)}\left\{\ln \left[\frac{X}{P}\right]\right\}^{2}+\phi_{31} V_{\text {pat }}+\phi_{32} V_{\text {golt }}+\phi_{33} V_{\text {unot }}+\phi_{34} V_{\text {cat }}+\phi_{35} C O_{\text {fiatt }} \\
& +\phi_{36} \mathrm{CO}_{g m t}+\phi_{37} \mathrm{CO}_{v w t}+\psi_{\text {uno }} \\
& W_{\text {cet }}=\alpha_{4}+\gamma_{41} \ln \left(P_{\text {pat }}\right)+\gamma_{42} \ln \left(P_{\text {golt }}\right)+\gamma_{43} \ln \left(P_{\text {unot }}\right)+\gamma_{44} \ln \left(P_{\text {cet }}\right)+\beta_{4} \ln (X / P L) \\
& +\frac{\lambda_{4}}{b(p)}\left\{\ln \left[\frac{X}{P}\right]\right\}^{2}+\phi_{41} V_{\text {pat }}+\phi_{42} V_{\text {golt }}+\phi_{43} V_{\text {unot }}+\phi_{44} V_{\text {cot }}+\phi_{45} C O_{\text {fiatt }} \\
& +\phi_{46} \mathrm{CO}_{g m t}+\phi_{47} \mathrm{CO}_{v w t}+\psi_{c e}
\end{aligned}
$$

em que os subscritos pa, gol, uno e ce representam as marcas Pálio, Gol, Uno e Celta, respectivamente, $W$ fornece a parcela de dispêndio com cada marca analisada no mercado; $P$ são os preços dos carros populares; $X / P L$ é o dispêndio real pela categoria de carros populares, formado pelo dispêndio nominal (X) dividido pelo índice de preço do QUAIDS, determinado na forma de uma função translog, $\left\{\ln \left[\frac{X}{p}\right]\right\}^{2}$ é o termo quadrático do $\ln \mathrm{X}$, isto é, do logaritmo do dispêndio; $V$ é o percentual de versões disponíveis no mercado; CO é o número de concessionária de cada montadora; $\alpha, \gamma, \beta, \lambda$ e $\phi$ são os parâmetros a serem estimados; e, $\psi_{p a}, \psi_{g o l}, \psi_{u n o} e \psi_{c e}$ são os erros de passeio aleatórios das equações de demanda do Pálio, Gol, Uno e Celta, respectivamente.

As variáveis explicativas adicionais ao modelo QUAIDS, referentes ao número de versões e o número de concessionárias, foram acrescentadas ao modelo, com o intuito de captar as possíveis influências dessas na demanda de carros populares, uma vez que esperavase que as variáveis possuíssem influência positiva na quantidade dispendida em cada marca.

Para a estimação das elasticidades de reação do preço para cada modelo, foram estimadas as equações (20) até (23): 


$$
\begin{aligned}
\ln p_{\text {pat }}=\theta_{1}+ & \varepsilon_{12} \ln p_{\text {golt }}+\varepsilon_{13} \ln p_{\text {unot }}+\varepsilon_{14} \ln p_{\text {cet }}+\phi_{51} V_{\text {pat }}+\phi_{52} D_{0}+\phi_{53} D_{1}+\phi_{54} D_{3} \\
& +\psi_{\text {ppa }} \\
\ln p_{\text {golt }}=\theta_{2}+ & \varepsilon_{21} \ln p_{\text {pat }}+\varepsilon_{23} \ln p_{\text {unot }}+\varepsilon_{24} \ln p_{\text {cet }}+\phi_{61} V_{\text {gol }}+\phi_{62} D_{0}+\phi_{63} D_{1}+\phi_{64} D_{3} \\
& +\psi_{\text {pgol }} \\
\ln p_{\text {unot }}=\theta_{3} & +\varepsilon_{31} \ln p_{\text {pat }}+\varepsilon_{32} \ln p_{\text {golt }}+\varepsilon_{34} \ln p_{\text {cet }}+\phi_{71} V_{\text {uno }}+\phi_{72} D_{0}+\phi_{73} D_{1}+\phi_{74} D_{3} \\
& +\psi_{\text {puno }} \\
\ln p_{\text {cet }}=\theta_{4}+ & \varepsilon_{41} \ln p_{\text {pat }}+\varepsilon_{42} \ln p_{\text {golt }}+\varepsilon_{43} \ln p_{\text {unot }}+\phi_{81} V_{\text {co }}+\phi_{82} D_{0}+\phi_{83} D_{1}+\phi_{84} D_{3} \\
& +\psi_{\text {pce }}
\end{aligned}
$$

em que, além das variáveis e parâmetros citados, aparecem a variável binária D que capta o efeito de sazonalidade trimestral nos preços dos veículos, onde os meses de outubro, novembro e dezembro formam o trimestre base, o $\varepsilon$ e o $\phi$ são parâmetros a serem estimados; e $\psi_{p p a}, \psi_{\text {pgol }}, \psi_{\text {puno }}$ e $\psi_{\text {pce }}$ correspondem aos erros aleatórios das equações de reação de preço do Pálio, Gol, Uno e Celta, respectivamente. Similarmente ao realizado no modelo QUAIDS, foram acrescentadas variáveis explicativas referentes ao percentual das versões que cada modelo disponibiliza no mercado e variáveis dummies, com a finalidade de captar os efeitos de sazonalidade no período analisado.

Os parâmetros do sistema formado pelas equações (16) a (19) são estimados por iterações que usam mínimos quadrados generalizados factível não-lineares (FGNLS), por meio do sistema de equações não lineares-lnsur. No que tange o sistema formado pelas equações (20) a (23), esse consiste em um modelo de Seemingly Unrelated Regression (SUR), isto é, equações aparentemente não relacionadas, estimadas por Mínimos Quadrados Generalizadas (MQG).

\subsection{Fonte de Dados}

Os preços e as versões dos modelos de carros populares foram coletados online na Fundação Instituto de Pesquisas Econômicas (FIPE) por meio da Tabela FIPE que fornece a média dos preços dos veículos no mercado nacional. Os dados referentes à produção de veículos por empresa, tipo e motorização de 1000cc obtidos nas tabelas estatísticas de 2005 a 2010 junto à ANFAVEA (2005-2010), com periodicidade anual, são proxys para as quantidades de carros vendidos por motorização e modelo, uma vez que os dados não são disponibilizados. Adicionalmente, os dados correspondentes ao número de concessionárias de cada montadora foram fornecidos, após solicitação, pelo Centro de Documentação da ANFAVEA - Cedoc $^{14}$. Por fim, por meio do uso das quantidades e preços, foram calculados os dispêndios para cada segmento do modelo analisado.

\section{Resultado e discussões}

\subsection{Elasticidade-preço direta e cruzada dos carros populares no Brasil de 2005 a 2010}

Para estimar a função de demanda para carros populares flex fuel no Brasil, foi utilizado o modelo QUAIDS com variáveis explicativas, características ao problema de pesquisa, no período compreendido entre agosto de 2005 e dezembro de 2010, totalizando 65 
observações. Foi empregado o valor igual a 20 para $\alpha_{0}$. A estimação das equações de demanda ou da parcela de mercado (equações 16-19) possibilitou a estimação das elasticidades-preço (direta e cruzada) Marshaliana ou elasticidades-preço não compensada apresentada na Tabela 1, bem como a estimação da elasticidade-dispêndio, por meio da equação (9), apresentada na Tabela 2.

Tabela 1: Elasticidade-preço (direta e cruzada) Marshaliana para carros populares flex fuel no Brasil 2005-2010

\begin{tabular}{ccccc}
\hline \hline & Pálio & Gol & Uno & Celta \\
\hline \hline \multirow{2}{*}{ Pálio } & $\mathbf{- 1 , 2 2 6 9 7 4 3 ^ { * * * }}$ & $0,800273^{@}$ & $-0,50535^{@}$ & $0,63197^{\text {NS }}$ \\
& $(0,443278)$ & $(0,48374)$ & $(0,312915)$ & $(0,549012)$ \\
\multirow{2}{*}{ Gol } & $0,63197^{*}$ & $\mathbf{- 1 , 3 5 3 4 ^ { * * }}$ & $-0,15747^{\text {NS }}$ & $-0,14805^{\text {NS }}$ \\
& $(0,337103)$ & $(0,515616)$ & $(0,232102)$ & $(0,494146)$ \\
\multirow{2}{*}{ Uno } & $-0,42585^{\text {NS }}$ & $-0,08537^{\text {NS }}$ & $\mathbf{- 1 , 8 7 8 0 5}^{* * *}$ & $1,891599^{* * *}$ \\
& $(0,384705)$ & $(0,409008)$ & $(0,330003)$ & $(0,433927)$ \\
\multirow{2}{*}{ Celta } & $-0,41034^{\text {NS }}$ & $-0,27491^{\text {NS }}$ & $1,773377^{* * *}$ & $\mathbf{- 2 , 1 5 2 3 8 ^ { * }}$ \\
& $(0,67547)$ & $(0,863349)$ & $(0,430853)$ & $(1,18599)$ \\
\hline \hline
\end{tabular}

Fonte: Resultados da Pesquisa.

Nota: Os valores entre parêntese correspondem ao erro padrão das elasticidades.

Nota²: Nível de significância: 1\% ‘***’, 5\% ‘**’, 10\% ‘*’ e 12\% ‘@’.

A maior parte das elasticidades estimadas (elasticidade-preço diretas e cruzadas e elasticidade de dispêndio) foi significativa a $12 \%$ de probabilidade. As elasticidades-preço diretas da demanda apresentaram sinais negativos e foram significativas a um nível de $10 \%$ de probabilidade.

Todas as elasticidades-preço diretas apresentadas para os carros populares mostraramse elásticas nos preços. As elasticidades-preço da demanda estimadas situaram-se entre $-1,22$ e -2,15. Tais valores foram maiores que as elasticidades estimadas no trabalho de Negri (1998), que analisou a elasticidade-renda e a elasticidade-preço da demanda de automóveis novos no Brasil na década de 90. Entretanto, vale salientar que em Negri (1998) todos os tipos de carros foram objetos de estudo, o que pode ter instigado o menor valor (em módulo) para a elasticidade. Ao analisar apenas os carros populares, carros mais acessíveis à população de baixa renda, as elasticidades-preço podem mostrar-se mais sensíveis a alteração no preço do produto.

Os modelos de carros populares que demonstraram maior sensibilidade ao consumo em relação aos preços foram o Celta (-2.15) e o Uno (-1.88), enquanto o Pálio (-1.23) e o Gol (-1.35), por outro lado, apresentaram menor sensibilidade. Embora todos os modelos analisados tenham apresentado demanda elástica, os modelos Pálio e Gol, os quais observaram a maior concentração de mercado durante o período estudado, foram os que apresentaram a menor elasticidade-preço da demanda em termos absolutos.

Devido ao fato da demanda do produto analisado ser elástica em relação ao preço, medidas de estímulo à economia por meio da elevação do consumo podem mostrar-se relevantes. Alvarenga (2010) avaliou os impactos da redução do IPI sobre as vendas de veículos no Brasil, entre janeiro e novembro de 2009. Os resultados do seu trabalho foram consistentes com os encontrados no presente estudo pois, a redução do imposto foi responsável por um aumento significativo nas vendas no período analisado.

Com relação às elasticidade-preço cruzada da demanda, apenas cinco foram significativas, das quais quatro possuem sinal positivo para o coeficiente estimado e uma, 
coeficiente negativo. Dessa forma, observa-se que para Gol e Pálio, as demandas foram diretamente relacionadas ao preço do outro automóvel em questão, caracterizando-os como bens substitutos. O mesmo relacionamento é verificado quanto o Uno e Celta, os quais também poderiam ser considerados bens substitutos entre eles. Por outro lado, quando o preço do Uno elevou-se em $1 \%$, ocorreu redução na quantidade de demanda do Pálio em $-0,50 \%$. A princípio, o sinal negativo encontrado para a elasticidade-preço cruzada da demanda do Pálio e do Uno mostraria indícios de bens complementares. Entretanto, como trata-se do mesmo bem (carros populares), isso não se aplica. A justificativa para o coeficiente negativo pode estar relacionada ao fato dos dois modelos populares serem da mesma montadora (FIAT) e possuírem denominadores em comum, tais como os custos de produção, entre outros fatores que podem ter influenciado a sua elasticidade-preço cruzada.

Outro fator que deve ser destacado é o coeficiente da elasticidade-preço cruzada que não foi significativamente diferente de zero, implicando que os bens são independentes. $\mathrm{O}$ modelo Celta não foi significativo no dispêndio do Gol, ou, o modelo Gol é independente de variações nos preços do Celta. Assim, com base na elasticidade para a definição de mercados relevantes dos produtos, o modelo Gol compete diretamente com o Pálio, estando no mesmo mercado relevante, assim como o modelo Uno compete com o Celta.

Como as elasticidades-preço estimadas sugeriram que Gol e o Celta não competiam diretamente, foi possível inferir que a montadora italiana Fiat possui dois modelos de carros populares justamente para que o Pálio rivalize diretamente com o Gol, enquanto o Uno o faça contra o Celta.

A elasticidade-dispêndio é apresentada na Tabela 2, sendo todos os coeficientes estimados significativos a $1 \%$ de probabilidade.

Tabela 2: Elasticidade-dispêndio para carros populares flex fuel

\begin{tabular}{cccccc}
\hline & Obs & Média & $\begin{array}{c}\text { Desvio } \\
\text { Padrão }\end{array}$ & Min & Max \\
\hline \hline Pálio & 65 & 1,314195 & 0,157790 & 1,134482 & 1,971498 \\
Gol & 65 & 0,951275 & 0,126234 & 0,643840 & 1,347868 \\
Uno & 65 & 0,648408 & 0,245625 & 0,011936 & 1,213235 \\
Celta & 65 & 1,081329 & 0,031175 & 1,018466 & 1,149550 \\
\hline \hline
\end{tabular}

Fonte: Resultados da pesquisa. Nota: todas as elasticidades foram significativas a 1\%.

A partir dos resultados reportados na Tabela 2, é possível verificar que o modelo Uno mostrou-se menos sensível em relação à alteração no nível de renda, comparado aos modelos Pálio, Celta e Gol. Possivelmente, isso decorre do fato que o Uno, como será abordado adiante, é um modelo que realizou, durante o período analisado, baixo investimento em inovação, concentrando esforços para manter-se como o carro mais barato nesse segmento. Segundo Negri (1998), a elasticidade-renda é menor para veículos menores e compactos e maiores em veículos mais caros e com itens de luxo.

Por fim, as elasticidades de reação dos preços são apresentadas na Tabela 3. 
Tabela 3: Elasticidade de reação dos preços dos principais carros populares. Brasil. 2005 $-2010$

\begin{tabular}{ccccc}
\hline \hline & LnP_Pálio & LnP_Gol & LnP_Uno & LnP_Celta \\
\hline \hline LnP_Pálio & --- & $-0,315693^{* * *}$ & $0,282685^{* *}$ & $0,347291^{* * *}$ \\
LnP_Gol & $-0,835906^{* * *}$ & --- & $1,00277^{* * *}$ & $0,539732^{* * *}$ \\
LnP_Uno & $0,234926^{* *}$ & $0,314732^{* * *}$ & --- & $0,089350^{* * *}$ \\
LnP_Celta & $1,263125^{* * *}$ & $0,741375^{* * *}$ & $0,391036^{* * *}$ & --- \\
Versões Pálio & $0,033447^{* *}$ & $0,025732^{* * *}$ & $-0,068360^{* * *}$ & $0,002910^{\text {NS }}$ \\
Versões do Gol & $0,036706^{* *}$ & $0,028498^{* * *}$ & $-0,073421^{* * *}$ & $0,002247^{\text {NS }}$ \\
Versões Uno & $0,037788^{* *}$ & $0,028641^{* * *}$ & $-0,068404^{* * *}$ & $-0,000148^{\text {NS }}$ \\
Versões Celta & $0,035375^{* *}$ & $0,027620^{* * *}$ & $-0,072653^{* * *}$ & $0,002641^{\text {NS }}$ \\
$D_{0}$ & $0,005196^{\text {NS }}$ & $-0,001130^{\text {NS }}$ & $0,002747^{\text {NS }}$ & $-0,001089^{\text {NS }}$ \\
D $_{1}$ & $0,000172^{\text {NS }}$ & $0,000793^{\text {NS }}$ & $-0,002457^{\text {NS }}$ & $0,000881^{\text {NS }}$ \\
$D_{2}$ & $0,002121^{\text {NS }}$ & $-0,006715^{\text {NS }}$ & $0,0112327^{\text {NS }}$ & $0,000589^{\text {NS }}$ \\
\hline \hline
\end{tabular}

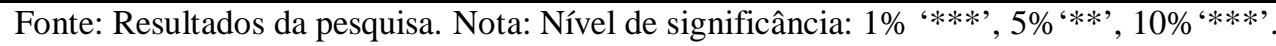

Todas as elasticidades de reação dos preços foram significativas a $5 \%$ de probabilidade. Como explicitado na Tabela 3, a concorrência via preço só pôde ser constatada nos carros que disputam a liderança do mercado (Pálio e Gol). Ademais, observou-se que a resposta do Pálio, segundo modelo com maior concentração de mercado, ao aumento de preço do Gol, modelo com maior concentração de mercado, torna-se mais agressivo $(0,84 \%)$ frente à resposta do Gol $(0,32 \%)$ quando o Pálio aumenta seu preço em $1 \%$. Os dados indicam um tipo de concorrência ou rivalidade entre o Gol e o Pálio na disputa pela primeira colocação dentre os modelos mais vendidos no mercado de carros populares.

Quando analisa-se a relação entre as marcas Pálio e Gol em relação ao Uno e Celta, observa-se uma situação de cooperação. Com isso, identifica-se que a concorrência via preço ocorre somente entre os modelos Gol e Pálio, já que para as demais interações entre os modelos, observa-se que os preços caminham no mesmo sentido, alterando, apenas, a magnitude. Contudo, esse tipo de análise requer uma avaliação mais criteriosa e profunda, conforme seção 4.2 .

Os parâmetros referentes às versões foram significativos no logaritmo dos preços, excetuando-se apenas a reação de preço do Celta que não teve nenhuma versão significativa. Os valores dos coeficientes das versões tiveram magnitudes muito próximas e obtiveram sinal negativo apenas na equação do preço do Uno. Entretanto, de maneira geral, verificou-se que introduzir uma nova versão no mercado possibilita, na maioria das vezes, aumentar o preço do carro popular. Pois, uma nova versão está relacionada à implementação de novas tecnologias e aperfeiçoamentos no design dos carros, fazendo com que isso possibilite o aumento no preço via diferenciação do produto. Adicionalmente, nenhuma das variáveis dummies acrescentadas ao modelo com o intuito de captar o efeito sazonalidade foram significativas.

\subsection{Análise do Poder de Mercado}

Os resultados para a análise do poder de mercado estão apresentados na Tabela 4, separadamente para o poder de mercado unilateral (índice de Rothschild (R)), poder de mercado cooperativo ou em conluio (índice de Chamberlin $(\mathrm{CH})$ ) e pelo poder de mercado total ou observável (índice de Cotterill (C)). 
Tabela 4: Elasticidades em nível de marcas e índices de poder de mercado - carros populares. Brasil, 2005-2010

\begin{tabular}{|c|c|c|c|c|c|c|}
\hline & $\begin{array}{c}\text { (1) } \\
\text { Elasticidade } \\
\text { Unilateral }\end{array}$ & $\begin{array}{c}\text { (2) } \\
\text { Elasticidade } \\
\text { Observada }\end{array}$ & $\begin{array}{c}\text { (3) } \\
\text { Elasticidade } \\
\text { de Plena } \\
\text { Colusão }\end{array}$ & $\begin{array}{c}(4) \\
\text { Índice de } \\
\text { Rothschild } \\
\quad(\mathrm{R}) \\
\mathrm{R}=(3) /(1)\end{array}$ & $\begin{array}{c}(5) \\
\text { Índice de } \\
\text { Cotterill } \\
(\mathrm{C}) \\
\mathrm{C}=(3) /(2)\end{array}$ & $\begin{array}{c}(6) \\
\text { Quociente de } \\
\text { Chamberlin } \\
(\mathrm{CH}) \\
\mathrm{CH}=1-(2) /(1)\end{array}$ \\
\hline Pálio & $-1,2269$ & $-1,6225$ & $-0,5148$ & 0,4196 & 0,3173 & $-0,3224$ \\
\hline Gol & $-1,3534$ & $-1,8817$ & $-0,6432$ & 0,4753 & 0,3418 & $-0,3903$ \\
\hline Uno & $-1,8780$ & $-1,7090$ & $-0,4903$ & 0,2611 & 0,2869 & 0,0900 \\
\hline Celta & $-2,1523$ & $-1,4589$ & $-0,4055$ & 0,1884 & 0,2780 & 0,3222 \\
\hline
\end{tabular}

Fonte: Resultados da pesquisa.

\subsubsection{Poder de Mercado Unilateral (Índice de Rothschild)}

Os resultados do índice R, poder de mercado unilateral, demonstram que o Gol, Pálio, Uno e Celta desfrutam do poder de mercado advindo da diferenciação de produto e/ou das barreiras à entrada de 47,53\%,41,96\%, 26,11\% e 18,84\%, respectivamente, do poder que apresentariam se as quatro marcas fossem administradas conjuntamente (monopólio). Destaca-se, ainda, que os maiores valores encontrados para o poder de mercado unilateral coincidem com as maiores concentrações de mercado, uma vez que o modelo Gol também é o maior detentor da concentração de mercado, com 0,34, seguido pelo Pálio, com 0,24, Uno, com 0,22, e Celta, com 0,20.

Possivelmente, a ocorrência do poder de mercado unilateral ocorre, principalmente, pela presença de inovações nos produtos (carro) com intuito de provocar diferenciação, a existência de fortes barreiras à entrada e a alteração do processo produtivo do segmento.

A observância da obtenção do poder de mercado unilateral por meio da inovação no setor automobilístico é advinda, presumivelmente, da diferenciação do produto que ocorre por meio de investimentos em motores mais modernos, modelos tecnologicamente mais equipados, design contemporâneo, entre outros. Assim, a indústria automobilística transforma-se para acompanhar as mudanças e exigências econômicas de um mercado cada vez mais competitivo. Dentre as mudanças adotadas pela indústria, destaca-se a necessidade de novos investimentos para a modernização do parque industrial, novas exigências dos consumidores quanto à qualidade do produto, estratégias locais orientadas pelas mundiais, entre outras (SILVA, 2001). Oliveira (2014) salienta que há eficiência da inovação quando ela é trabalhada como um diferencial competitivo no segmento de carros populares, aumentando o volume de vendas das principais montadoras desse segmento.

Além dos esforços voltados para a introdução de inovação para a diversificação do produto, a presença de barreiras à entrada no setor automobilístico exerce grande influência na determinação de poder de mercado unilateral. Santos e Pinhão (1999) sumarizam a estratégia de gestão das montadoras e autopeças instaladas no país afirmando que essas estão investindo em plantas de grande escala, sendo necessário, assim, alto investimento, principal barreira à entrada de outros concorrentes no mercado.

Ainda quanto às barreiras, ressalta-se que para o mercado de carros populares, o preçolimite $^{15}$ é mais alto do que para os demais segmentos, o que pode ser explicado pela oferta escassa de veículos importados com essa motorização pois, houve Ademais, a oferta dos carros populares, anterior à abertura comercial para carros importados, era realizada quase que exclusivamente por quatro montadoras (Volkswagen, Fiat, General Motors, Ford) , as

\footnotetext{
${ }^{15}$ Ver mais sobre preço limite em Hasenclever e Kupfer (2002).
} 
quais reuniam vantagens tecnológicas na produção automobilística no Brasil. Essa vantagem das firmas já estabelecidas no Brasil funcionava como uma proteção de mercado (SILVA, 2001).

Com relação às políticas de crescimento das montadoras, Volkswagen, Fiat, e a General Motors do Brasil (Chevrolet), pode-se verificar um aumento na desverticalização do processo produtivo. A Volkswagen adota a política de single sourcing ${ }^{16}$, isto é, adotando único fornecedor para cada família de peças, por modelo, com a finalidade de reduzir tempo e custo no desenvolvimento de produtos. A General Motors (Chevrolet), que produz automóveis no Brasil desde 1959, alterou sua estratégia a partir da década de noventa para também colocar os fornecedores junto à fábrica, atuando com um sistema de produção fundamentado na cadeia de valor co-participativo entre cliente (montadora) e fornecedor (autopeças e serviços) (SILVA, 2001). A estratégia da montadora em possuir um único fornecedor faz com que haja limitação no número de fornecedores de peças, gerando dificuldades para as montadoras que tinham interesse em estabelecerem-se no mercado encontrar fornecedores.

No que concerne os modelos dos carros populares, é apresentado a seguir uma comparação entre esses, buscando justificar a existência de valores diferentes para o poder de mercado unilateral.

O Celta apresentou o mais baixo poder de mercado unilateral, o que pode ser devido ao fato de ter sido o último dos quatro modelos a chegar ao mercado (no ano 2000). Embora tenha conseguido diferenciar-se tendo sua capacidade técnica sendo avaliada positivamente, talvez por sua regularidade e por seu conjunto mecânico eficiente, com boa combinação de desempenho e consumo, os consumidores apontaram críticas quanto à falta de modernização no acabamento, ao ruído, ao desgaste prematuro de lonas e tambores de freios e ao motor 1.0 da GM, o qual foi considerado como de concepção antiga e com pouca suavidade (QUATRO RODAS, 2013), fatores que podem ter dificultado a aceitação desse modelo no mercado.

Durante uma parte considerável do período presente no mercado, o Fiat Uno não sofreu grandes mudanças estéticas e/ou inovações no seu design, mantendo-se, assim, o DNA batizado pela Fiat de "rounded-square" (o quadrado arredondado). Para compensar o acabamento padronizado, o Uno precisou custar menos. Em 2007, o Fiat Uno Mille ainda era o carro mais barato do Brasil, isto é, com mais de vinte anos de mercado, esse popular sempre teve como um dos principais atrativos o seu preço, além do fato do investimento no baixo custo de manutenção, com peças e serviços, geralmente, mais em conta se comparados aos seus concorrentes (CARPLACE, 2014).

Similarmente, o Pálio é considerado um carro popular bem simples, e um dos fatores que, possivelmente, fidelizam os consumidores é a economia de gasolina dos dois modelos. Entretanto, uma vantagem do Pálio perante o Uno, que pode ser relevante para a determinação do poder de mercado unilateral, é o seu projeto mais moderno, com avanços em segurança ativa (como a suspensão, de comportamento mais previsível) e passiva (como o estepe no porta-malas, bem mais seguro em colisões que no cofre do motor) (QUATRORODAS, 2010).

O Gol teve o maior poder de mercado unilateral, possivelmente, por esse modelo ter passado por renovações significativas e, embora mantendo suas proporções originais, foram aplicadas as linhas presentes nos novos modelos mundiais da Volkswagen. No período analisado, o Gol destacou-se por meio de seu design mais moderno, sendo perceptivos os detalhes em peças como o spoiler traseiro e os retrovisores externos, com formato aerodinâmico. Ao comparar o painel de controle do Gol com as demais marcas, foram observadas semelhanças que remetiam, principalmente, ao Uno e ao Pálio. Já ao considerar a qualidade do acabamento, a Volkswagem é considerada por analistas do setor automobilístico

\footnotetext{
${ }^{16}$ Ver Silva (2001) para mais informações sobre a política single sourcing.
} 
como superior às demais. Sobressai-se, também, em relação à menor quantidade de ruídos provenientes do painel, bancos, portas, cintos de segurança e para-sóis, por exemplo. Por outro lado, o Gol destaca-se, negativamente, quando compara-se o seu preço com demais concorrentes, uma vez que dos quatro modelos analisados, o Gol possui a média de preços mais elevada (QUATRO RODAS, 2010).

Outro fator importante, levado em consideração no momento da aquisição de um carro novo, é a segurança (FARIAS, 2008). O órgão responsável pelo controle da segurança nos veículos novos no Brasil e no Caribe, o Latin NCAP ${ }^{17}$, criado em 2010, ao avaliar a segurança dos carros populares novos em 2010, constatou que o nível de segurança dos veículos oferecido no Brasil estava aquém, se comparado ao norte Americano e ao Europeu. Entretanto, dentre os carros populares aqui analisados, em uma escala até cinco estrelas, destacam-se o Gol e o Pálio, com três estrelas para segurança no transporte de passageiros adultos e duas estrelas para o transporte de passageiro infantil. O Uno obteve uma estrela para o transporte de passageiro adulto e duas estrelas para passageiro infantil (sendo esta avaliação realizada em agosto de 2011) e o Celta, duas estrelas para a segurança do transporte de passageiro infantil e nenhuma estrela para segurança do passageiro adulto (avaliação realizada também em 2011) (LATIN NCAP, 2014).

Desse modo, os modelos de carros populares com maior poder de mercado unilateral são aqueles que também apresentam maior nível de segurança para passageiros adulto e infantil; estando em melhor avaliação o Gol e o Pálio, seguidos pelo Uno e, por último, o Celta (LATIN NCAP, 2014).

\subsubsection{Poder de Mercado Cooperativo ou Colusivo (Chamberlin (CH))}

Na coluna 6 da Tabela 4, constata-se que dois valores dos coeficientes de Chamberlin (CH) possuem sinais negativos (Gol e Palio), demonstrando a existência de rivalidade entre eles, e dois possuem valores positivos (Uno e Celta), demonstrando a existência de cooperação entre esses modelos.

O valor de - 0,39 do quociente de $\mathrm{CH}$ do Gol evidencia que as firmas não agem coordenadamente. Pelo contrário, é a marca que encontra mais rivalidade frente às concorrentes. Quando o Gol aumenta o seu preço (ou reduz sua produção), as demais marcas passam a cobrar preços menores (ou produzem mais), com o intuito de conquistar parte do mercado do Gol, reduzindo a liderança desse no que tange às vendas de carros populares. Talvez devido ao fato do Gol possuir a maior concentração de mercado dos carros populares, os demais modelos tendem a diminuir tal vantagem, aumentando a concorrência no mercado.

Com o valor de $-0,32$ no quociente $\mathrm{CH}$, o Pálio também enfrenta comportamento de rivalidade das demais marcas diante de suas ações. Entretanto, embora a magnitude da reação das outras firmas seja menor, se comparada à rivalidade enfrentada pelo Gol, essa diferença não é muito grande.

Uma vez que o poder de mercado é formado pelos poderes unilateral e cooperativo, e esse último é negativo para o Gol e o Pálio, essas marcas terão o seu poder de mercado total (índice C) reduzido pela rivalidade. Destarte, o poder de mercado total ou final para essas respectivas marcas será sempre menor se comparado ao poder unilateral, resultante do efeito de rivalidade das outras firmas do mercado.

Em contrapartida, o valor positivo do Celta no índice $\mathrm{CH}$ implica que a cooperação com as demais firmas permite-lhe, de maneira geral, ter poder de determinação de preço equivalente a 32,22\%, se comparado ao que teria em colusão total. Para o Celta, o conluio ou cooperação entre os modelos é vantajoso, uma vez que não usufrui de alto poder unilateral.

\footnotetext{
${ }^{17}$ Programa de Avaliação de Carros Novos na América Latina e Caribe.
} 
Com relação ao Uno, pode-se atribuir a mesma analogia empregada no parágrafo anterior, isto é, o valor positivo para o índice de $\mathrm{CH}$ implica que as demais firmas demonstram uma cooperação com ela e isso lhe confere um poder de mercado de $9 \%$, se comparado ao que teria em colusão total.

\subsubsection{Poder de Mercado Total ou Observável (índice de Cotterill (C))}

A partir do índice C, apresentado na coluna (5) da Tabela 4, contata-se que, combinando os dois efeitos apresentados anteriormente ( $\mathrm{R} \mathrm{e} \mathrm{CH}$ ), o Gol é o modelo de carro popular que possui o mais alto grau de poder de mercado, apresentando $34,18 \%$ do poder que teria um monopolista. Salienta-se ainda que, essa marca não possui acréscimo ao poder de mercado decorrente da cooperação das demais marcas. Pelo contrário, como essa defronta-se com rivalidade ou concorrência no mercado, há redução no seu poder de mercado unilateral.

O Pálio apresenta o segundo maior poder de mercado, com $31,76 \%$ do poder que teria um monopolista. Destaca-se que o Pálio também encontra competição no mercado, enfrentando concorrência das demais montadoras.

Já o Uno e o Celta, que apresentam menores índices de concentração de mercado (CR4) e menores índices de poder de mercado unilateral (R), também apresentam menores índices (C), isto é, menor poder de mercado observável, 0,28 e 0,27 , respectivamente. Vale destacar que a diferença entre o poder de mercado observável dos modelos Uno e Celta $(0,28$ e 0,27$)$ não torna-se tão expressiva se comparado ao Pálio e ao Gol $(0,32)$. Isso porque, ao diferentemente do Gol e do Pálio, que apresentaram rivalidade, o Uno e o Celta têm seu poder de mercado total acrescido, devido à existência de cooperação entre seus modelos. Assim, uma das justificativas para o elevado valor do poder de mercado observável no Celta, 27,8\%, estaria relacionada ao alto poder de mercado cooperativo ou colusivo $(32,22 \%)$ que são combinados ao índice (R) para obtenção do índice (C).

Os resultados encontrados para as estimativas do poder de mercado total ou observável, possivelmente, estão associados à concentração de mercado no segmento de carros populares da indústria brasileira. Verificou-se que, os modelos de carros populares que possuíam maior concentração de mercado (definido pelo CR4) apresentaram maior poder de mercado, com ressalva para os anos de 2005, no qual o Uno possuía maior concentração de mercado seguido pelo Gol, Celta e Pálio, e em 2010, quando o Classic Sedan entrou para o CR4, tendo o Gol o maior nível de concentração, seguido pelo Classic Sedan, Celta e Uno.

\section{CONCLUSÃO}

Todas as elasticidades diretas dos carros populares foram negativas e elásticas, isto é, o consumo desse segmento reage mais que proporcionalmente a alterações no seu preço. Essa ocorrência é constatada empiricamente, uma vez que o baixo custo dos carros populares torna-os mais atrativos perante aos outros segmentos, como os de motorização 1.4 ou 1.6 cilindradas, por exemplo.

Ao analisar as elasticidades cruzadas, notou-se que o segmento pode ser separado em dois mercados, nos quais o Gol e o Pálio competem entre si, sendo considerados, assim, como bens substitutos. Paralelamente, o Celta e o Uno também são classificados como bens substitutos um do outro.

No que concerne os fatores que, possivelmente, determinam o poder de mercado unilateral, pode-se identificar, principalmente, as barreiras à entrada e as inovações. Em menor proporção, destaca-se também a classificação das condições de segurança do veículo. Nesse sentido, o Gol obteve maior poder de mercado unilateral, seguido pelo Pálio, Uno e Celta. 
Ademais, constatou-se a existência de concorrência (ou rivalidade) entre o Gol e o Pálio, e cooperação entre os modelos Celta e Uno. Uma vez que a elasticidade da demanda é inversamente relacionada ao poder de mercado, tem-se que o poder de mercado do Gol e do Pálio é reduzido pela existência de rivalidade ou concorrência entre esses modelos. Nesse sentido, a cooperação existente entre o Uno e o Celta faz com que a elasticidade observada seja menor à elasticidade unilateral, levando o poder de mercado total observado ser maior ao unilateral.

Ao considerar o poder de mercado total ou observado, o Gol foi o modelo de carro popular com o maior grau de poder de mercado, seguido pelo Pálio, Uno e Celta. Embora os valores encontrados para os poderes de mercado não sejam tão altos (próximos de 1), os valores para os carros populares são significativos.

Não obstante, destacam-se os resultados referentes às elasticidades-preço da demanda direta pois, ao encontrá-las elásticas, constata-se que essas elasticidades não determinam a existência do poder de mercado no segmento de carros populares, contrariando o que, normalmente, espera-se ao utilizar a corrente da NEIO, que relaciona a existência do poder de mercado à elasticidade-preço da demanda inelástica.

Um fator que pode ter influenciado o poder de mercado nesse segmento é a razão de concentração (Crk) pois, os modelos que apresentaram maior concentração, também obtiveram maior poder de mercado. Entretanto, essa afirmação deve ser utilizada com cautela, uma vez que o modelo em questão não testa empiricamente a correlação entre as variáveis de razão de concentração e poder de mercado.

Assim, o presente estudo contribui ao identificar e mensurar o poder de mercado de carros populares e seus possíveis determinantes na economia brasileira. Sugere-se, como desdobramentos futuros, a mensuração da perda de bem-estar social no mercado de carros populares. Pois, como todas as empresas possuem valores positivos para o índice de poder de mercado observado, o mercado certamente sofre perda de bem-estar.

\section{REFERENCIAL BIBLIOGRÁFICO}

AGUIAR, D. R. D. Mensuração de poder de mercado por meio de dados de marcas comerciais: modelos, limitações e aplicações. Revista de Economia Política, v.20, n. 3, jul./set. de 2000, p. 152-162, 2000.

ALVARENGA, G. V. Políticas anticíclicas na indústria automobilística: Uma análise de cointegração dos impactos da redução do IPI sobre as vendasde veículos, Texto para

Discussão, Instituto de Pesquisa Econômica Aplicada (IPEA), No. 1512, 2010.

ALVES, L. S. e WILBERT, M. D. Redução do Imposto sobre produto industrializado e a venda de automóveis. XI Congresso USP Iniciação Cientifica em Contabilidade. Novas Perspectivas na Pesquisa Contábil, São Paulo, Julho de 2014.

ANFAVEA - Associação Nacional dos Fabricantes de Veículos Automotores -. Anuário da Indústria Automobilística Brasileira: 2014. 156p. ANFAVEA: São Paulo, 2014. [10 de maio de 2014]. <http://www.virapagina.com.br/anfavea2014/>.

- Associação Nacional dos Fabricantes de Veículos Automotores -. Anuário da Indústria Automobilística Brasileira: 2012. 158p. ANFAVEA: São Paulo, 2012. [10 de junho de 2014]. <http://www.anfavea.com.br/anuario.html>.

- Associação Nacional dos Fabricantes de Veículos Automotores - Tabelas Estatísticas. 2005, 2006, 2007, 2008, 2009 e 2010. [10 de agosto de 2014] Disponíveis em < http://www.anfavea.com.br/tabelas.html >. 
BAKER, J. B. \& BRESHNAHAN, T. F. “The Gains from Merger or Collusion in Product Differentiated Industries.” Journal of Industrial Economics, 33 (June):427-443, 1985.

BANKS, J.; BLUNDELL, R.; LEWBEL, A. Quadratic Engel curves and consumer demand. The Review of Economics and Statistics, v. LXXIX, n. 4, p. 527-539, Nov. 1997.

BLUNDELL, R.; PASHARDES, P.; WEBER, G. What do we learn about consumer demand patterns from microdata. American Economic Review, v. 83, n. 3, p. 570-597, June 1993.

BOlter, W. G.; MCCONNAUghey, J. W.; KELSEY, F. J. Telecommunications Policy for the 1990s and Beyond. ME Sharpe, 1990.

CADE -CONSELHO ADMINISTRATIVO DE DEFESA ECONÔMICA- Resolução no $\mathbf{1}^{\mathbf{1 8}}$ de 25 de novembro de 1988. Disponível em:

$<$ http://www.cade.gov.br/lehislacao/resolucoes/18reso198.asp>.

CARPLACE. Revista. Galeria: 30 anos de história do Fiat Uno no Brasil.2014. [Acessado em 5 de janeiro de 2015]. Disponível em <http://carplace.uol.com.br/galeria-30-anos-de-historiafiat-uno-brasil/>.

CASOTTI, B. P.; GOLDEnSteIn, M. Panorama do Setor Automotivo: as mudanças estruturais da indústria e as perspectivas para o Brasil. BNDES, setembro, 2008.

CERQUEIRA, L. S.; SILVA, A. B. da; FARIAS, V. T.. Consumidor de Baixa Renda: Uma Analise dos Fatores que Influenciam a Aquisição de Automóveis em Salvador. Revista de Administração e Contabilidade da FAT, v. 5, n. 2, p. 111-128, 2013.

CHURCH, J.; WARE, R. Industrial Organization: a strategic approach. New York: Irwin McGraw - Hill, 2000. 832 p.

COTTERILL, R.W.; FRANKLIN, A. W.; MA, Y. L. Measuring market power effects in differenciated product industries: an application to the soft drink industry. Food Marketing Policy Center, Storrs, University of Connecticut, no 35 (October), 62p, 1996. [01 de novembro de 2014]. (http://www.fmpc.uconn.edu/publications/rr/rr32.pdf ).

COSTA, Cleusa; DA ROSA, Eliamar Maciel. Indústria automobilística paranaense de 2002/2005: a concentração do mercado. Ciências Sociais em Perspectiva (6) 2007.

DEATON, A. and J. MUEHLBAUER. An almost ideal demand system. American Economic Review 70 (3), 312-326. Economics and Consumer Behaviour. Cambridge: Cambridge University Press, 1980.

FARIAS, C. A., Poder de Mercado no segmento de picapes pequenas da indústria automobilística brasileira/Christiano Alves Farias. - Viçosa: MG. Tese de doutorado. Universidade Federal de Viçosa, 2008.

GABRIEL, L. F., SCHNEIDER, A. H., SKROBOT, F. C. C., e de Souza, M. Uma análise da indústria automobilística no Brasil e a demanda de veículos automotores: algumas evidências para o período recente. Anais do $39^{\circ}$ Encontro Nacional de Economia, ANPEC-Associação Nacional dos Centros de Pós-Graduação em Economia, 2011.

GREER, D. F. Industrial Organization and Public Policy. 2nd ed. New York: Macmillan, 1984. 
HASENCLEVER, Lia; KUPFER, David. Economia Industrial: fundamentos teóricos e práticas no Brasil. Rio de Janeiro: Campus, 2002. P. 73-90.

LATIN NCAP - Latin New Car Assessment Programme. Resultados 2014. [Acessado em 5 de janeiro de 2015]. Disponível em <http://www.latinncap.com/po/resultados>.

MARTIN, Stephen. Industrial organization in context. Oxford University Press, 2010.

OLIVEIRA, M. S. S. A inovação como diferencial competitivo no segmento de carros populares no Setor Automobilístico Brasileiro [Manuscrito]/ Mário Sergio Silva Oliveira. 2014.

POI, B.P. Easy demand-system estimation with quaids. The Stata Journal 2012. Number 3, pp. 433-446.

QUATRO RODAS. Revista. Celta X Clio X Mille X Ka X Palio X Gol. Carros Comparativos. Abril, 2010. [Acessado em 5 de janeiro de 2014]. Disponível em < http://quatrorodas.abril.com.br/carros/comparativos/celta-x-clio-x-mille-x-ka-X-palio-x-gol548898.shtml>.

. Revista. Fiat Uno Vivace 1.0 Evo X Vw Gol 1.0 total flex. Carros comparativos. Junho, 2010. [Acessado em 5 de janeiro de 2015]. Disponível em < http://quatrorodas.abril.com.br/carros/comparativos/fiat-uno-vivace-1-0-evo-X-vw-gol-1-0total-flex-568648.shtml>.

Revista. Comparativo dos 1.0 completos. Por Hairton Ponciano Voz e Péricles Malheiros. 23 de setembro de 2014. [Acessado em 5 de janeiro de 2015.]. Disponível em <http:/quatrorodas.abril.com.br/carros/comparativos/comparativo-1-0-completos802127.shtml>.

SANTOS, Ângela Maria Medeiros M. \& PINHÃO, Caio Márcio Ávila. Pólos Automotivos Brasileiros. BNDES. Setorial, Rio de Janeiro, n 10, p. 173-200, set. 1999.

SILVA, C. L. Competitividade e estratégia empresarial: um estudo de caso da indústria automobilística brasileira na década de 1990. Revista FAE, Curitiba, v.4, n.1, p.35-48, jan./abr. 2001.

SILVA, W. V.; CAVALARI, M. M. A.; ONOFRE, R. H. e DEL CARSO, J. M. Análise do grau de concentração da indústria automobilística brasileira e sua relação com a participação no mercado. Revista de Negócios, v. 13, n. 1, p. 93-107, 2008.

SILVA, M. M.C. Demanda domiciliar por frutas e hortaliças no Brasil. Universidade Federal de Viçosa. Dissertação de Mestrado, fevereiro de 2013.

VIDEIRA, R. A. Uma análise da concorrência no setor brasileiro de celulose. 2005. Tese (Dissertação de Mestrado) - Escola de Economia de São Paulo - Fundação Getúlio Vargas FGV, São Paulo, 2005. 
Anexo 1

Razão de concentração dos quatro principais modelos do segmento de carros populares flex fuel de 2005 a 2010

\begin{tabular}{lc|c|c|c|c|c}
\hline \hline & $\mathbf{2 0 0 5}$ & $\mathbf{2 0 0 6}$ & $\mathbf{2 0 0 7}$ & $\mathbf{2 0 0 8}$ & $\mathbf{2 0 0 9}$ & $\mathbf{2 0 1 0}$ \\
\cline { 2 - 7 } & $\%$ & $\%$ & $\%$ & $\%$ & $\%$ & $\%$ \\
\hline \hline GOL & 20,96 & 21,61 & 21,21 & 23,15 & 22,03 & 21,71 \\
PALIO & 15,93 & 19,2 & 19,62 & 15,75 & 15,57 & 9,63 \\
UNO & 23,33 & 15,27 & 13,53 & 13,66 & 14,82 & 10,97 \\
CELTA & 17,32 & 16,16 & 13,26 & 12,34 & 9,41 & 11,34 \\
FOX & 14,71 & 8,78 & 7,78 & 6,53 & 8,52 & 6,96 \\
CLASSIC & 0,00 & 5,94 & 4,38 & 5,24 & 7,08 & 12,71 \\
SEDAN & $\mathbf{7 7 , 5 4}$ & $\mathbf{7 2 , 2 4}$ & $\mathbf{6 7 , 6 2}$ & $\mathbf{6 4 , 9}$ & $\mathbf{6 1 , 8 3}$ & $\mathbf{5 6 , 7 3}$ \\
CR4 & &
\end{tabular}

Fonte: Elaboração própria a partir de dados dos Boletins da ANFAVEA (2005 a 2010). 